\title{
Understanding mass participatory pervasive computing systems for environmental campaigns
}

\author{
Alan Chamberlain - Mark Paxton - Kevin Glover - Martin Flintham - Dominic Price • \\ Chris Greenhalgh $\cdot$ Steve Benford $\cdot$ Peter Tolmie $\cdot$ Eiman Kanjo • Amanda Gower • \\ Andy Gower · Dawn Woodgate · Danaë Stanton Fraser
}

Received: 1 December 2012/Accepted: 19 May 2013/Published online: 11 December 2013

(C) The Author(s) 2013. This article is published with open access at Springerlink.com

\begin{abstract}
Participate was a 3-year collaboration between industry and academia to explore how mobile, Web and broadcast technologies could combine to deliver environmental campaigns. In a series of pilot projects, schools used mobile sensors to enhance science learning; visitors to an ecological attraction employed mobile phones to access and generate locative media; and the public played a mobile phone game that challenged their environmental behaviours. Key elements of these were carried forward into an integrated trial in which participants were assigned a series of environmental missions as part of an overarching narrative that was delivered across mobile, broadcast and Web platforms. These experiences use a three-layered structure for campaigns that draw on experts, local groups and the general public, who engage through a combination of playful characterisation and social networking.
\end{abstract}

\footnotetext{
A. Chamberlain $(\bowtie) \cdot$ M. Paxton $\cdot$ K. Glover $\cdot$ M. Flintham · D. Price · C. Greenhalgh - S. Benford · P. Tolmie

Mixed Reality Lab, University of Nottingham, Jubilee Campus, Wollaton Road, Nottingham NG8 1BB, UK

e-mail: alan.chamberlain@nottingham.ac.uk

E. Kanjo

College of Computer and Information Sciences, King Saud

University, Malaz Campus, Riyadh, Saudi Arabia

A. Gower - A. Gower

BT, Adastral Park, Martlesham, Ipswich, Suffolk IP5 3RE, UK

D. Woodgate $\cdot$ D. S. Fraser

Department of Psychology, University of Bath, Bath BA2 7AY, UK
}

\section{Introduction}

At the turn of the twenty-first century, we have become involved in a global debate about the nature and impact of climate change and our role as individuals and societies in managing this. To pursue this debate, we must address three key challenges. We need to gather information about the environment on a greater scale than ever before, including scientific measurements, documentation of local conditions and accounts of people's behaviours. We need to inform debate by conveying environmental knowledge in new ways that engage the widest possible audience. Ultimately, we will also need to persuade people to change their behaviours.

Pervasive computing has the potential to play a unique and vital role in addressing these challenges. Networks of wireless sensors can gather data on an unprecedented scale [1], while millions of mobile camera phones can annotate scientific measurements with documentation of local environmental conditions [2-4]. Context-aware computing [5] can deliver environmental information in situ, engaging people at the most appropriate times and locations [6]. Finally, a new generation of mobile experiences such as pervasive games that are interwoven with the patterns of daily life and our location [7] may reach new audiences, encourage them to participate and persuade people to reflect on and change their behaviours. In short, we believe that pervasive computing can ultimately engage millions of people in mass participation environmental campaigns, raising awareness of environmental issues, supporting education, activism and democracy, and delivering environmental data on a scale never before possible. The literature [8] demonstrates the breadth and depth of the research, relating to the new and rapidly evolving fields of pervasive, persuasive computing and their application to environmental-behavioural change. 


\section{The Participate project}

There is an established history spanning more than 20 years of 'big science' projects in the UK in which broadcasters encourage the nation to gather data that are then distilled and fed back through television programmes. For example, the BBC's annual Springwatch ${ }^{1}$ series harnesses the reach of television to recruit hundreds of thousands of people to record the first signs of spring in their gardens, each contributing to an evolving national map of climate change. The emergence of pervasive computing can greatly enhance such campaigns by enabling the public to document the world about them in far richer detail, while also delivering analysis to them in context, directly enhancing their understanding of a particular place or activity.

Building on this tradition, Participate was a UK project that based itself within the tradition of citizen science and the use of IT [9] and in particular mobile technologies as environmental sensors [10]. The project brought together broadcasters (BBC), telecommunications companies (BT), computing companies (Microsoft), sensor manufacturers (ScienceScope), artists (Blast Theory) and universities (Nottingham and Bath) to explore the potential of pervasive computing to support widespread participation in environmental campaigns. Our collective aim was to explore how the convergence of mobile, online and broadcast media might enable a broad cross section of the public to contribute to, as well as access, environmental information-on the move, in public places, at school and at home. We followed the approach of 'research in the wild' in which iterative public trials and observational studies of emerging technologies inform the generalisation of broader concepts and platforms. In the early stages of the design cycle of the project, we consulted with institutions such as the World Wildlife Fund and used information provided from the Energy Savings Trust in order to further understand the issues associated with behavioural change in regard to environmental issues. Throughout the design cycle, we also fed in the feedback that arose from each of the trial stakeholders, for example. feedback from teachers and children for the Schools Trial. Our first iteration involved three complementary pilots in different settings (the Schools Trial, Stories@Kew and Prof Tanda), while the second drew these together into an integrated cross-platform campaign called Bicker Manor. A key feature of the research was to take the research into real-world settings [11] in order to appropriately understand the sociotechnical dimensions on the systems.

$\overline{1}$ BBC Springwatch, http://www.bbc.co.uk/springwatch/.

\section{The Schools Trial}

Young people can be especially passionate about the environment, and schools are frequently the focal points of their communities. We therefore set out to explore how mobile sensing could enhance science learning in schools by enabling groups of students to capture and analyse environmental data from their locality. In the first trial, we worked with two classes in different schools (ages 13-15), loaning them laptops, specialised sensing and data-logging hardware, mobile phones running noise-sensing applications, disposable cameras and notebooks. The students took turns to take this data collection equipment on their daily journeys to and from school over a 2-week period, measuring the levels of carbon monoxide (CO), temperature and ambient noise as they went. They then downloaded their individual data logs to ScienceScope's graphing software in order to display them as time series line graphs. They also visualised their data in Google Earth, for example showing on a 3D map the levels of carbon monoxide encountered along the route. In addition to the data, the students also collected photographs and handwritten notes that provided some extra contextual information to help explain the data. The idea was to produce a snapshot of the conditions that each student experienced on a daily basis and thus promote discussion and reflection about how they experience different kinds of pollution on their journeys.

Video analysis, observation and interviews were carried out. The pupils were found to be engaged by the Google Earth visualisations and the data trails provoked considerable discussion about the routes taken, and possible causes of the data peaks. They also raised other interesting issues, such as how this type of technology could potentially be used for surveillance purposes, with possible implications for personal safety if this type of technology were used inappropriately. However, an almost equally high level of engagement was elicited by the other materials that the pupils had collected, even though these seemed quite bland in comparison to the Google Earth trails, which feedback suggests was because the material was personally significant to them, reflecting their own individual activities [12]. Pupils at one school decided to make posters with the 'lowtech' materials that they had gathered, to record what they had done and display their results.

To further extend the debate around these science experiments, we ran a ' $60 \mathrm{~s}$ scientist' film-making workshop at each school. Groups of pupils were encouraged to make very short films centred on the trial activities. Each group was given a topic or question such as 'debate issues around monitoring your environment' using technology upon which to base their ideas and was shown how to storyboard, shoot and edit their own short film. The day 

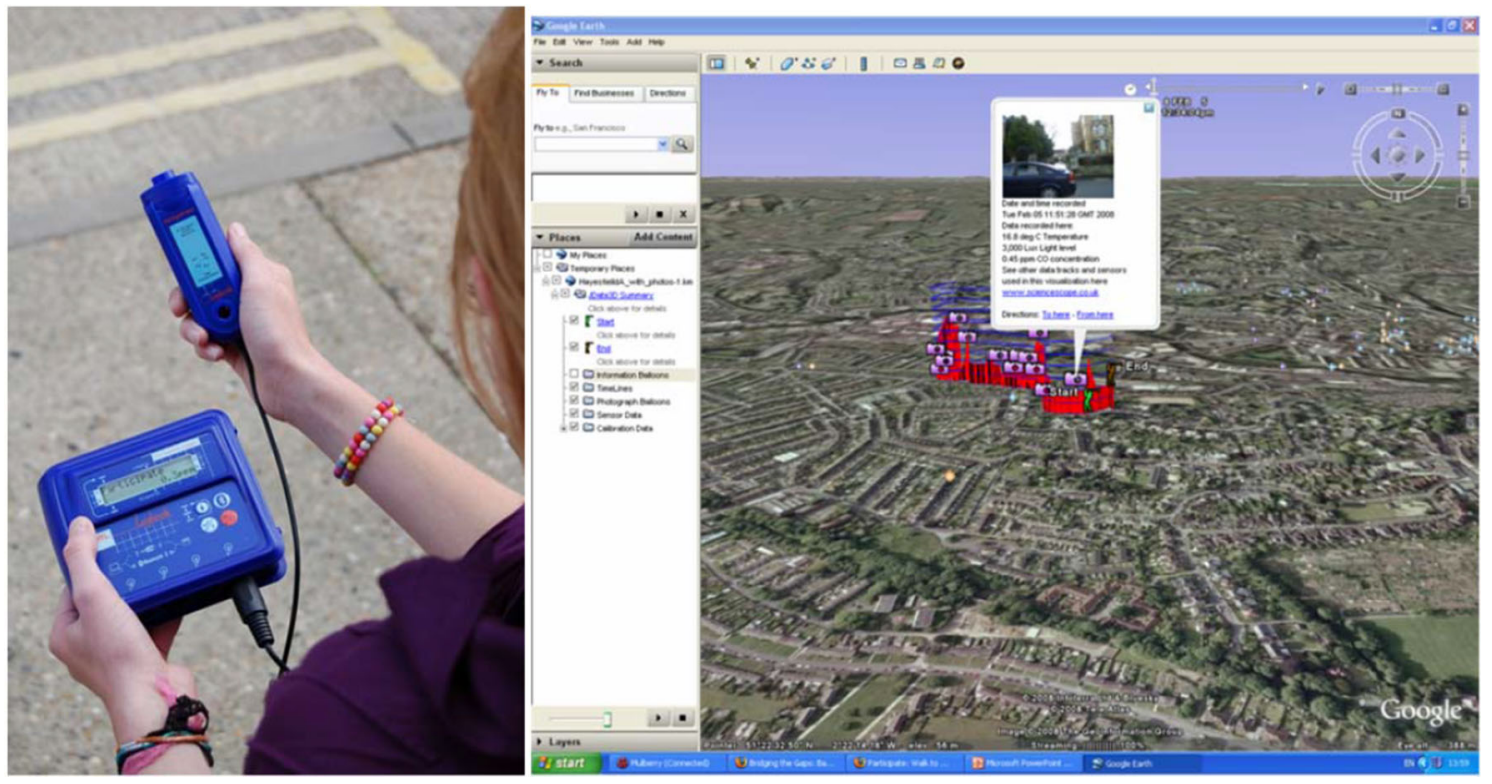

Fig. 1 Measuring carbon monoxide and displaying the results, with image and text annotations, in Google Earth

finished with a general viewing of all the films, which provoked further intensive discussion and debate. Producing and sharing material based on the activities, and scientific findings was found to motivate children to reflect upon what they had learned and to seek out more information on the topic [13].

Next, we widened participation to include a larger number of schools, developing software to more easily integrate data from sensors and data loggers (Fig. 1) with digital photographs and annotations and display the results as traditional graphs and also in Google Earth and Google Maps (Fig. 1, right). We also developed a secure website (www.participa teschools.co.uk) to enable new schools to easily join the trial and existing schools to share and compare their data. Teachers could set up student groups, manage access to different areas of the site and upload data and supplementary class work such as digital posters and short films. The end of the trial had involved fifteen schools. Finally, towards the end of this trial, we also experimented with the rapid deployment of our approach and supporting technologies at major events such as the World Scout Jamboree, during which scouts were invited to collect sound data from around their campsite, with a view to constructing a 'sound map' of the site to be presented on a public display [14].

\section{Understanding the Schools Trial}

\subsection{Students' reflections on the 'Summer School' visits}

The overall impression given by the young people interviewed (a total of 16 students) was that the 'Summer
School' and Participate project was that they very much enjoyed the experience and clearly gained a lot from it. For many, it was the first time that they attended some of the sites and attractions and clearly learnt a lot from the trips to Drax power station and the eco-farm about new approaches to energy consumption. All groups spoke animatedly about the camp and using the Participate Schools website. Given the nature of the 'Summer School' trips, it is worth reflecting on some of the points raised by the young people, as they directly complement the overall goals of the Participate project and potentially provide value insights for the project.

\subsection{New learning, simple actions}

All three of the schools groups interviewed demonstrated through their retelling of the 'Summer School' visits that they had learnt a great deal about different approaches to environmentalism and energy consumption and production. They discussed the merits of the Drax power station and coal and energy consumption, and its by-product (see below extract).

AB: Another thing about Drax is it recycles its waste, 'cause it burns coal and that produces ash, and they've created like a nature reserve and hills out of this ash. (Participant, AB: Group B, Interview)

Others discussed how the Vikings lived and used 'cow dung' to make huts, lights and so forth. The purpose for bringing the young people to the Viking centre was to show how people lived in the past, with much less energy and used everyday by-products could be used to create various 
energy solutions. Some young people also commented on how in the eco-building they went to see used recycled glass to make interesting and 'beautiful' building interiors. The design of the products was referred to twice in two separate interviews and clearly for some how an object looks is as relevant as how environmentally sound it is.

One of the key issues that the young people discussed was the use of rapeseed and plants to create bio-fuel products. During the week, they also created posters about the process of turning rapeseed into fuel. These posters were created using paper and will be displayed at the farm and at Newcastle University. ${ }^{2}$ The extract below also indicates how the young people discussed the ideas they had encountered with each other after the trip, debating in particular how some rapeseed is grown but not used and how other plants could be harvested for their oil. Given that the young people engaged so much with the concept of bio-fuel, it is not surprising that they spoke at some length about it and also debated its merits as a 'future fuel'. The following conversation demonstrates how the young people are aware of the markets, costs and production needs for creating bio-fuel solutions and how the cost of it is different in the UK and France. They also realise that bio-fuel is one of a number of solutions that we need to consider.

In discussing other possible actions for changing our lifestyles and becoming more environmentally aware, many of the young people related the visions of the future to their everyday experiences, for example school journeys, car-pooling and better use of country buses. The following extract specifically relates it to their local area.

Like more, like less buses around the countryside people who need to get to school. There's like two buses that come from $\mathrm{X}$, like, like when we're sixteen or something - some people on one bus, then twenty odd on another and it's like two big buses going on and like both of them coaches could fit into one. So ...(Participant, RH: Group A, Interview)

The following extract also indicates how much the young people had taken on-board from the 'Summer School', recognising how 'simple' actions can be 'effective'. In the extract below, they acknowledge that their 'opinions' have changed but 'whether' they decide to go home and 'get rid of this big jeep' will be a big step and 'take time' for people to do. For them, acknowledging that they have to make such choices as young people and adults is a positive indicator, even it means downsizing from a 'Mercedes' to a 'Mini'.

\footnotetext{
${ }^{2}$ Unclear the exact nature of the relationship with Newcastle University but the school has strong connections with some departments.
}

RH Maybe just like doing the simple things like switching lights off and like all that kind of stuff that, even though it's simple, that can actually help

EM Simple but effective

RH And it's renewable

AB The-the, I think we can all find our say that we have changed our opinion, but whether we'll want to go home ...

EM Yeah

AB $\ldots$ and say, oh, let's get rid of this big jeep ...

CS Yeah, 'cause you know they're not going to, 'cause ...

AB ... you know, big four litre Mercedes' and BMWs. I know that - who-and, would you go home-I think it's going to take a long time to get this ...

EM Yeah

AB $\quad \ldots$ sorted

EM Some people aren't going to do that, it's ...

EB It's kind of like when you're older ...

EM ... they're not going to take their money

EB It's kind of like when you're older, and you buy your own car

AB Yeah

EM Don't buy one of them. Buy like a tiny one you can-not like a, you know, not one of those rubbish ones, but like a nice ...

T (Laughs). A nice little Mini

(Participant EM and AB: Group A, Interview)

In summary, it is clear from the above extracts and sequences that the young people learnt a great deal through the 'Summer School' visits. As discussed earlier, the young people extended their thinking about the merits of various different forms of environmental action and how they and their families could contribute to making a change. The message that small steps can lead and help towards making significant changes is one that has hit home and within this context is supported and extended within their school, community and home contexts. Given this multiple approach and the young people's serious contemplation about the issues, one could conclude that these young people will potentially make positive steps and take onboard the learnings from the 'Summer School' week.

\subsection{Teachers' reflections on Participate website}

It was clear from the teachers' interviews that both the Deputy and Assistant Head of School A, highly valued the possibilities that the Participate project brought to their school. The reasons for this are that it clearly tied well into the existing curriculum and extra-curricular activities that the school was promoting and the educational ethos. This was central to the success of the project in this school. One 
finding from the early school trials was schools need to 'see' the incentive and value in a project, before committing to 'run' with it.

Value was also placed on how the Participate project could 'showcase' what the schools were doing and how it could link or 'introduce' different subjects around a central 'environmental' theme, while simultaneously supporting cross-curricula, interdisciplinary projects.

So it's a question of introducing it, um, the Participate website a, as a way of showcasing what we do within the curriculum. Um, once it's up and running within the geography curriculum it will have a knock on effect into other areas. Um, other subjects are becoming more aware of putting environmental issues into their, into their curriculum so, therefore, you know, the science department will use - could well be using that data log. The maths department are always happy to process data and to, you know, take relevant data and actual factual data that students have collected and use that in, within their work so it will have a trickle out effect throughout the ...(Teacher Interview)

To make the process 'easier' and to support the integration of the sensors, it was also suggested that Participate demanded in some ways for teachers to collaborate (e.g. geography teachers with ICT teachers and so on).

Um, to make the process easier I would work with the ICT department and see if, if the actual use of the data loggers could be incorporated into part of the IC, students' ICT experiences, um, within the school. They each, each class experiences at least an hour of, of specific ICT time, so we could perhaps ...so it wouldn't have to be the geography time, so the students area aware of that. Because the data loggers have got such wide usage...(Teacher Interview)

What is also clear is that teachers need to play with the equipment well in advance of the time they are planning lessons. This was a major flaw in the July trial. Kit was 'loaned' to schools and only a limited amount was available. School A only received the kit on the day the 'Summer School' began: alongside the pressures of finalyear wrap up and administration, the school did not have the time to play or experiment with the kit before the 'Summer School'. Therefore it sat in boxes until the BBC team arrived.

....we will have this equipment twenty-four ... seven, and so on, that we can actually, you know, tie that in with our curriculum, which is what we're looking at already. You know.... We're looking to be more flexible...... of using this kind of equipment and maybe getting involved in the project. I mean at the minute it's just me, myself, and, you know, Martin whose ... just come in this week interested and so on, and I think, you know, you're looking at maybe a group of children who are called the project team or whatever. (Teacher Interview)

Aside from the operational or curricula logistics of learning how to use the data-logging kit, it is also necessary for teachers to engage with the Participate website. The site offers many features, which although are part and parcel of the 'Web 2.0' experience are not yet commonly available to schools in the format presented by the Participate website. Unfortunately prior to the trial taking place, the school had not engaged with the website and not even logged on or set up the class groups etc. Engaging with the website on this level is very easy but again teacher time constraints prevent this from happening. As a result, the team had to show the teachers how to log on and engage with the site. In revisiting the school, this had to be done again and indicates how much schools need to be 'spoon-fed' projects as they have not got the time to pick them up and run with them on their own. It is difficult to know how to explicitly within a small team address this issue as it simply boils down to continuously putting the pressure on teachers and working at the ground level with them, until they feel comfortable to take the project on. At the time of writing this paper, this is now happening with School A.

Summary of teacher concerns and needs:

Time constraints This is the biggest issue with teachers. They simply do not have the time necessary to learn how to run new projects. The project has to be explicitly linked to what they are aiming to do either within or outside of their curriculum plans; they have to see the value and reason in taking on the project. There has to be an incentive.

People management Staffing and taking on new projects require managing people. Initial instigators or champions may not necessarily be the teachers who run the projects and often they do not have the time to train others. Materials related to the project need to be clear and easy to transfer to others.

Knowing what is expected from them The project needs to explicitly state what it wants from schools. Schools cannot afford to input time into a project, which has not clear benefits for them. Consequently, Participate needs to 'spell-it-out' for the teachers.

Costs of equipment If schools are to engage with the sensing activities related to the Participate project website, they need to have the equipment all the time. This requires either buying or loaning the kit for extended periods of time. However, the cost of the kit is off-putting, 
particularly if schools already have sensing kits. The added advantage of buying the ScienceScope kit is that they can use the visualisation data, which is considered as a value aspect of the project. However, cost always remains an issue.

Support and the co-production of knowledge with others Value was placed on learning from other peers. The possibility for teacher to share lesson plans and view other schools' contributions was considered as a very attractive element of the Participate project, particularly the ability to share data across schools.

Taking what you do into the community For School A, this was an important aspect of the educational goals and philosophy. Although not all schools may take this position for many reasons, this makes School A, an ideal partner for the Participate project.

\subsection{Pupils' reflections on using the Participate website and media}

Overall the pupils' feedback at School A was very positive. Pupils discussed how they found the site to be 'novel', 'impressive' and 'fun'. The young people commented on the fact that they could engage with other schools in a way that they considered as unique. Comparison was also made to how the site was structured like a 'lesson', which was easy to follow and that it allowed you to add different media. None of the pupils reported any problems with logging on, accessing or navigating the site.

'It's, it's, it's really nice, because it's, um, because it's got loads of other schools and other people that you can see what they're trying to do to help the environment as well, so ...(Participant EM: Group B, Interview)

'I think it's, like, impressive 'cause, like, you sort of get thought what you can do and not, like. It's like a lesson really - and then you can, like, use different pictures and all that, and ......(Participant CS: Group $\mathrm{B}$, Interview).

Specifically, comments were made on the creation of online posters and films, which were the most successful activities that the young people engaged with. Few commented on the sensing activity, which for some did not work out, as they were not able to connect their equipment correctly: for example, connecting the data loggers and retrieving the information from them was hit and miss. It was not clear why this happened as all necessary software was installed and there was no problem with the equipment. Most of the problems were solved by downloading the data on to another computer but why the logger connected to some computers in the ICT suite and not other was unclear. Additionally, when the young people used the GPS Garmin, they had not cleared them before started so although that collected data successfully when they retrieved it, it did not match to their location. Feedback on the help material also indicated that the material created by ScienceScope could be clear. The following points summarise the main points raised by the young people during their interviews.

\section{Conclusions and next steps}

To conclude, the findings from School A are positive, yet simultaneously highlight the constraints that exist in adopting the Participate Schools project. Understandably from a school's perspective, the appropriate allocation of a teacher's time and resources is an issue, along with the need for more full-time project management support within the Participate Schools team. Regarding these issues, it is difficult to know what can be achieved on limited budgets and with limited resources. What is clear is that when working with schools, projects need to be approached over a 2-3 year basis as schools are flexible or in a position to embed a new project into their curriculum without serious consideration and clear incentives.

From a content and technology perspective, there have been no major issues raised around the Participate website with regard to the film and online poster tools. The technology was seen in a positive light, as some authors [14] have suggested that technology offers us ways of being sustainable in the world. Some design issues have been raised with regard to the online poster format, but these are small points (e.g. need to provide an indication of image size on the poster etc.).

In relation to the environmental sensing kit; although the young people did not specifically raise any issues with the kit, this is perhaps because not all young people successfully managed to complete this part of the project, was limited. Therefore a complete picture is not available. However, key issues that were raised included:

- The cost of the ScienceScope sensing kit, particularly if schools already have a sensing kit, they are not convinced of the value in buying a second set. Although they did appreciate the value of the Google Earth and Map visualisations, this is perhaps not enough for them to buy extra kit. The loaning of kit has also shown not to be the most fruitful or scalable model.

- Clearing of GPS Garmin - this is not an 'obvious' thing to do and easy to forget. Teachers and pupils need to be 

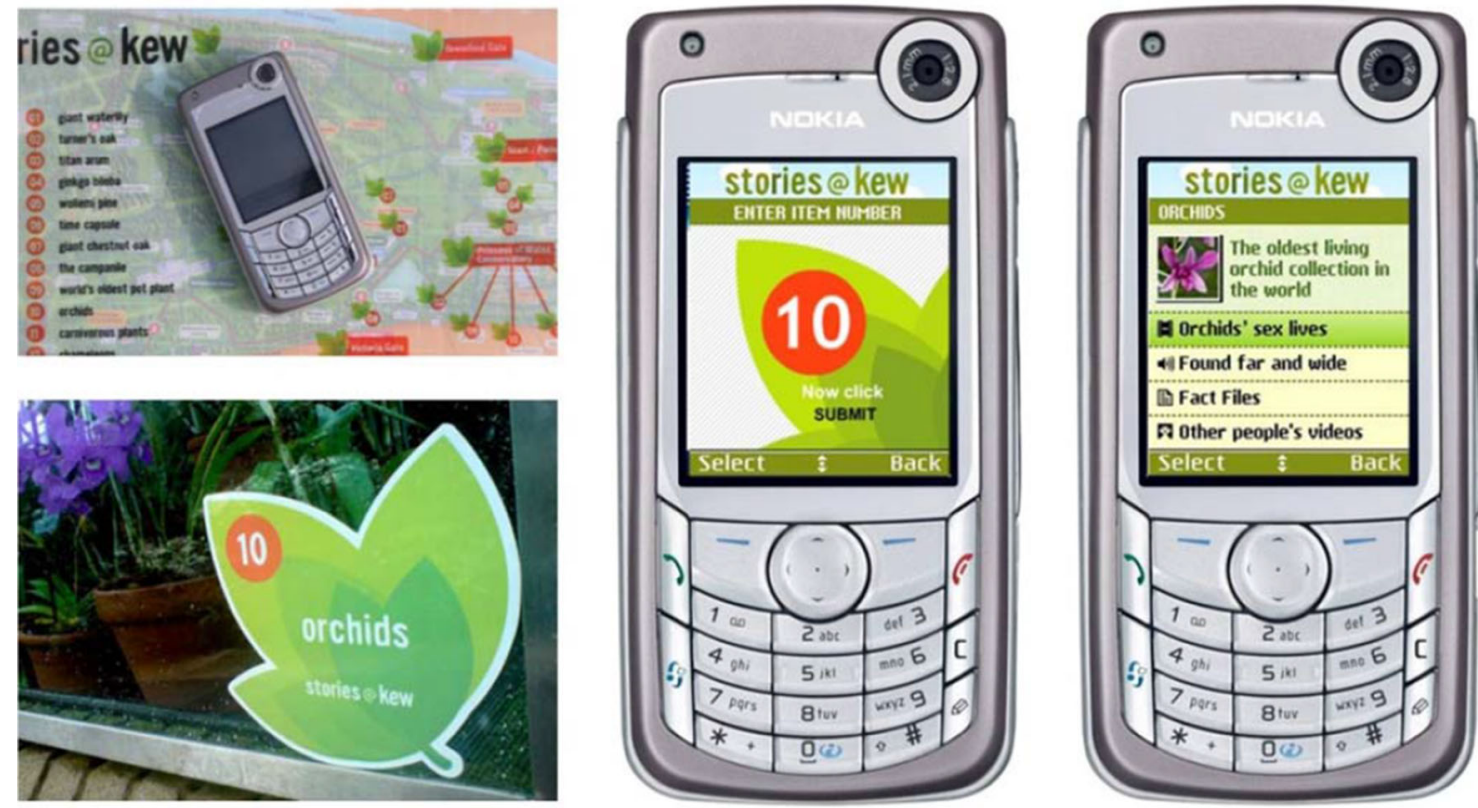

Fig. 2 'Low-Tech’ Map, located signage and Stories@Kew phone application

more supported with appropriate training when using this kit in schools.

- Reading the ScienceScope kit and GPS data-once both pieces of kit are 'on' they start working. For some young people, understanding this took some time as they thought, they needed to 'do more' or turn something else on. Again, time, preparation and clear instructions are central to ensuring that this kit is correctly used within a classroom context.

These findings indicate that for schools, lack of time, daily school routines and too many additional commitments are key issues. In working with schools, particularly on a project such as Participate, it is very difficult to overcome such barriers and we need to be realistic and innovative if we are to overcome these stumbling blocks. What this hopefully should not mean is that we give up on working with schools but that we consider different ways with which to engage them such as through afterschool clubs, community initiatives and project-based work. This does require planning and investing in working with a school/schools over a prolonged period of time. Unfortunately, this is not always achievable in short bursts or on limited resources. It requires investment but the benefits particular for a project with aims such as Participate have a ripple effect as demonstrated by the 'Summer Camp' to engage parents and communities. To this end, working with schools in such a way, through after-school clubs, holiday camps and so forth is a very productive approach for this project to take in the coming year.

\subsection{Stories@Kew}

Another route to engaging people with environmental issues is through visitor attractions that champion environmental themes. The Royal Botanical Gardens at Kew in London is one such attraction, combining a leading research centre working at the forefront of conserving plant life worldwide with a major public attraction set in 300 acres of parkland. This provided the setting for our second trial, in which we explored how visitors could use mobile phones to access and create location-based media [15]. Stories@Kew invited members of the public to explore Kew Gardens and discover bundles of media virtually located at key points of interest (POIs) distributed throughout the park. On discovery of a POI, participants were able to view professionally created editorial material as well as user-generated content (UGC) from previous visitors, after which they were asked a question and prompted to publish their own stories in return.

Two systems were trialled. Our 'low-tech' approach as shown in Fig. 2 used a Nokia 6630 mobile phone, a physical map and signage placed at each POI location. Once a user had made their way to a POI using the provided map, they keyed in the number displayed on the signage in order to access the relevant media. This system also used a third party GPRS media communications service provided by $\mathrm{Shozu}^{3}$ to upload user-generated videos to a specified email account that was monitored by the production team.

\footnotetext{
${ }^{3}$ Shozu, http://www.shozu.com.
} 
Fig. 3 'High-Tech' GPS supported Stories@Kew phone application
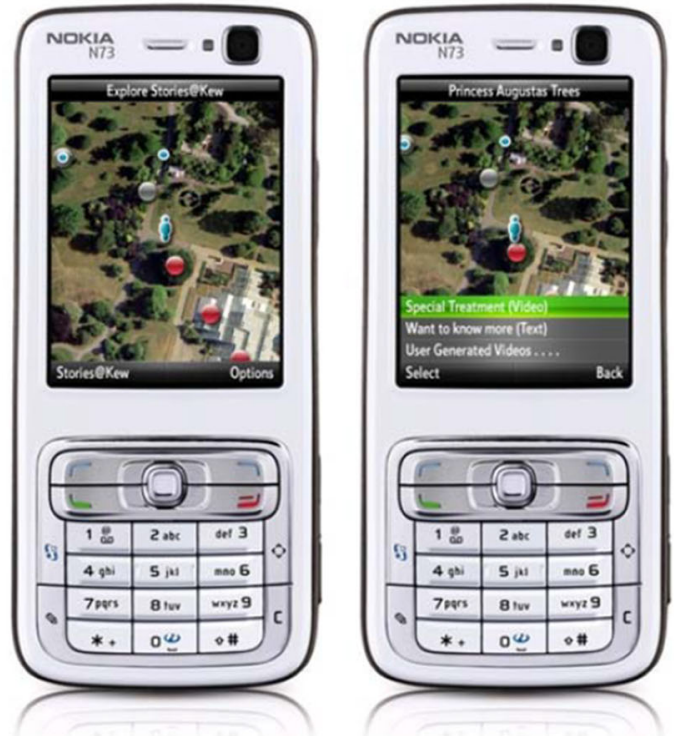

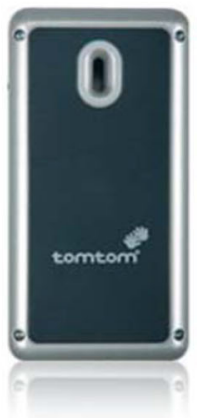

Our original 'high-tech' approach as shown in Fig. 3 used a Nokia N73 paired with a TomTom GPS receiver. The use of GPS and battery-powered Bluetooth transmitters located at POI sites enabled the phone to be 'POI aware' both inside and outside of buildings. An on-screen map showed the location of the user and of each POI. On encountering a POI, the phone rang and displayed a menu for accessing the local media. Videos created by the user were also location-tagged and represented on the map with a blue dot.

Both systems were able to access a core of 13 POIs. An additional 21 virtual POIs, which had no physical signage, were provided only for the high-tech version. Each POI provided access to bundle of editorial videos, audio and text, along with a 'call-to-action' in the form of a question, which prompted the user to create a video. A selection of user-generated video clips specific to that location were also made available.

Selected UGC videos were also looped on a public screen in the Stories@Kew recruitment room and uploaded to the public area of the Stories@Kew website. All UGC created by a participant was subsequently made available to them within a private password-protected area of the Stories@Kew website.

Three hundred users trialled Stories@Kew. Our observations, interviews and questionnaires revealed that both the editorial media and UGC engaged users. Although UGC was generally accessed less than the editorial content, participants were typically still able to recall a favourite user-generated video clip. We found that being able to view others' content was an important part of the creative content generation process, with participants referencing others' videos before creating their own responses. Our call-to-action prompts appeared to be useful for directing participants to create what we judged to be 'on topic' responses. Many participants willingly adopted the prompt for their video, with parents and friends often taking the role of an interviewer using the prompt as a starting question. We also asked participants to rate key motivations for participation in the experience and the desire to 'see my stories on the Stories@Kew website' was strong across all responses.

\subsection{Understanding Stories@Kew}

Initially there were difficulties with the choice of hardware, which created usability and practical problems. Small buttons on the phone, the requirement to use the phone camera outside the application to create high-resolution videos, both meant it was easy for the user to unexpectedly quit from the application. It was necessary to alter the interface to make it easy for the user to restart.

Environmental issues also impacted on the experience: standard problems such as sunlight on the screen made the map difficult to view, busy places were hard to record in and the audio was difficult to hear. In order to overcome this, solutions were implemented, such as headphones, and the careful positioning of POIs and attention to contrast ratios on screen could have helped solve these.

Using the map has pros and cons for the user. Although participants felt they had relatively good indications of where they were, they found that orientation was difficult and it was requested that this also be included as part of the interface. The relationship of the POI to the map and the real location was at times difficult to pinpoint (for example a POI relating to a tree amidst the forest was ambiguous), whereas a POI in relation to a point on the floor in a building (the time capsule was easy to locate). 
Our participants were very enthusiastic about the concept of a device that could be carried unobtrusively and would alert you to places of interest. Not having to browse a device or enter a number was viewed as beneficial; this virtual tap on the shoulder was positively received. This was reflected in the users' focus on both audio and vibratealerts, as opposed to watching the map and waiting for a POI to flash on-screen. Participants could be looking at the gardens around them rather than having to split their attention and gaze at the screen.

The overall feedback indicated that this was an enjoyable and interesting experience that could be used in other locations, from museums to city environments and even the theatre. Feedback suggested that the emphasis on exploration, having content linked to locations and being able to create content were the three key pillars of engagement.

We felt that families benefited from the inclusion of technology and the experience format during their visit the most. They were the most productive of our groups, and parents felt their teenagers would not have enjoyed coming out with them without the use of the technology. Families tended to start and end together with some time apart doing their own thing in between.

Individuals and couples tended to explore much further afield, going of to quiet areas, possibly away from families and busy areas. There were no common participatory trends amongst these groups.

Participants had no problems remembering the content they had viewed, and they revealed information that was relevant to where they were, was important and was key to their experience.

Prompts were problematic for some participants. On the negative side, one person did not want to be told what to do-the most extreme response. However, the difficulty for some was more the tone and type of question: gardening questions for those without a garden were difficult to answer, and reflective or personal questions were too challenging for some. There was an overall preference for active, fun and simple-to-film prompts, although some of the UGC that was reflective appealed to the users who watched them.

There is still more work that could be done on analysis of actual content created. People took turns filming each other when they could, there were interview styles between the camera operator and the responder, narration over the top of the scenes, and more creative shots being employed.

We feel this was successful in terms of directing participants. When we think of the number of videos employed as seed material, the investment in 14 archive videos and 40 interview videos generated over 90 response videos in a small number of trialists. There were additional 141 own videos some of which also had the potential for creating new POIs in the system. However, 233 videos in total for a team to manually moderate in 4 days proved to be a lot of work.

There was a strong desire to see the content on the website by the participants and this was reflected in some attempting to login the evening of their visit. However, the website was only live for a short time.

Our hope for exploitation is to capitalise on emerging mobile phones in order to exploit new technologies. Devices that are robust and commonplace in the market will make development of the applications much easier. Aspects of the experience could be run on lent devices at venues in a controlled environment now but systems would need to be in place to help manage content and moderate content.

\subsection{Prof. Tanda's Guess-A-Ware}

Our third early trial focused on engaging individuals as they went about their daily activities rather than in the specific context of a classroom or visitor attraction. We created a context-aware game for mobile phones called Prof. Tanda's Guess-A-Ware. Games have been used in an attempt to engage people with green issues previously [16], but we wanted to build a picture of the player's environmental behaviour over a period of several weeks, inviting them to reflect on or even change their daily routines and to understand what explicitly motivated people to participate in environmental campaigns such as this [17].

Prof. Tanda is a character that lives on a player's phone and interacts with them for just a few minutes each day, asking them to answer questions, perform a task or share an activity with nearby people. He will typically initiate contact once a day, although players are free to contact him more frequently if they wish. He is portrayed, in a cartoon style, as being entertainingly egocentric; a quirky character who combines serious questions with playful ones, is obviously well informed about the environment, and yet is not infallible and is shown to have somewhat suspect tastes. His aim was to entertain players while also informing and provoking them, but without being patronising or 'preachy'. Figure 4 shows a series of screenshots from an example session in which Prof. Tanda instructs a player to measure the amount of water they consume when taking a shower.

The key to activities such as this is delivering them in context; that is, at those moments when players will be able to engage in them (e.g. at home in the early morning when they might be ready to take a shower). Consequently, the game also gathers context information to inform decisions about how to schedule activities for individual. Whenever Prof Tanda contacts a player, he plays a guessing game in which he attempts to guess their current location. The 


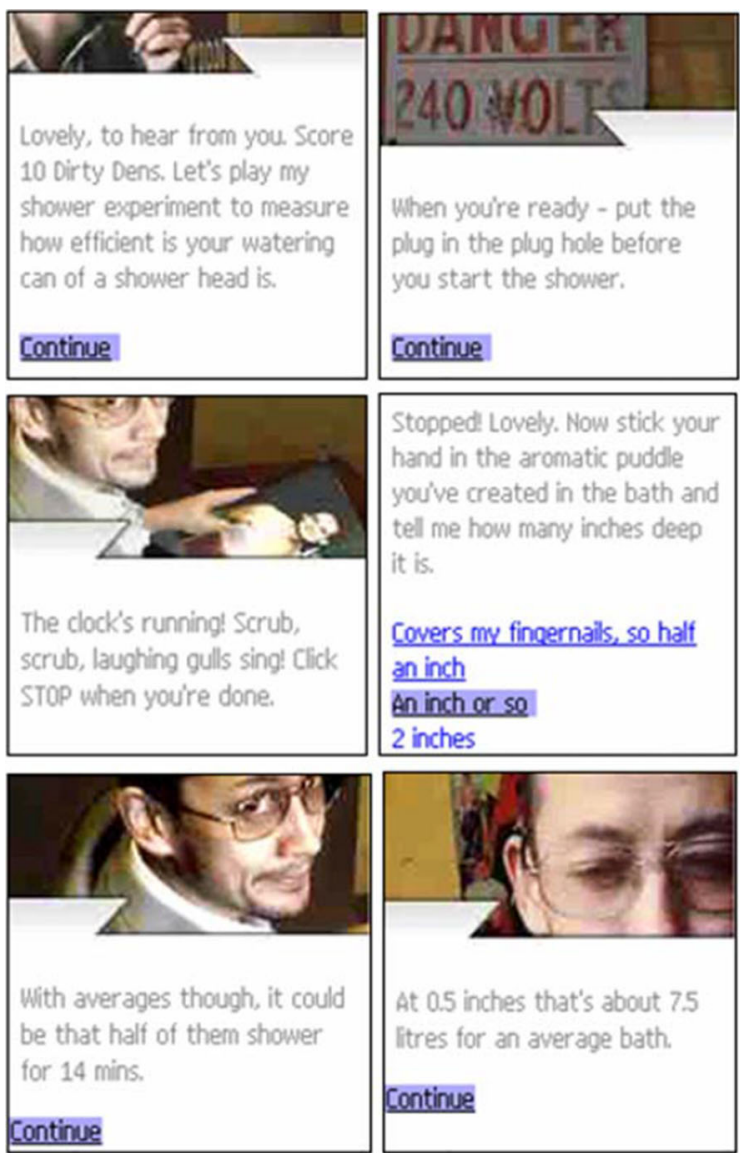

Fig. 4 An example session with Professor Tanda

player either confirms his guess or in cases where he guesses incorrectly, is asked to give the correct answer. The answer is associated with their current mobile phone cell ID taken as a rough indicator of their location and the current time of day. Prof. Tanda also asks questions about the players' daily routines. For example, in one early session it asks on which day the player takes their rubbish bins out for collection, which is then used to schedule an activity about recycling on their next bin day. The net result is a game that tries to gradually learn about and adapt to the player's routine, engaging them in environmental activities at appropriate moments. In the initial trial, a human operator inspected the context information each evening in order to schedule the next day's sessions so that these can be downloaded onto the phone. Future more scalable versions of the game would need to automate this process, drawing on the human operators' decisions from the first trial to develop an automated model of context and session allocation.

The initial trial involved 30 players over 2 weeks, with feedback being gathered through questionnaires and system logs of interactions. In general, players reported enjoying their interactions with Prof Tanda, especially the use of

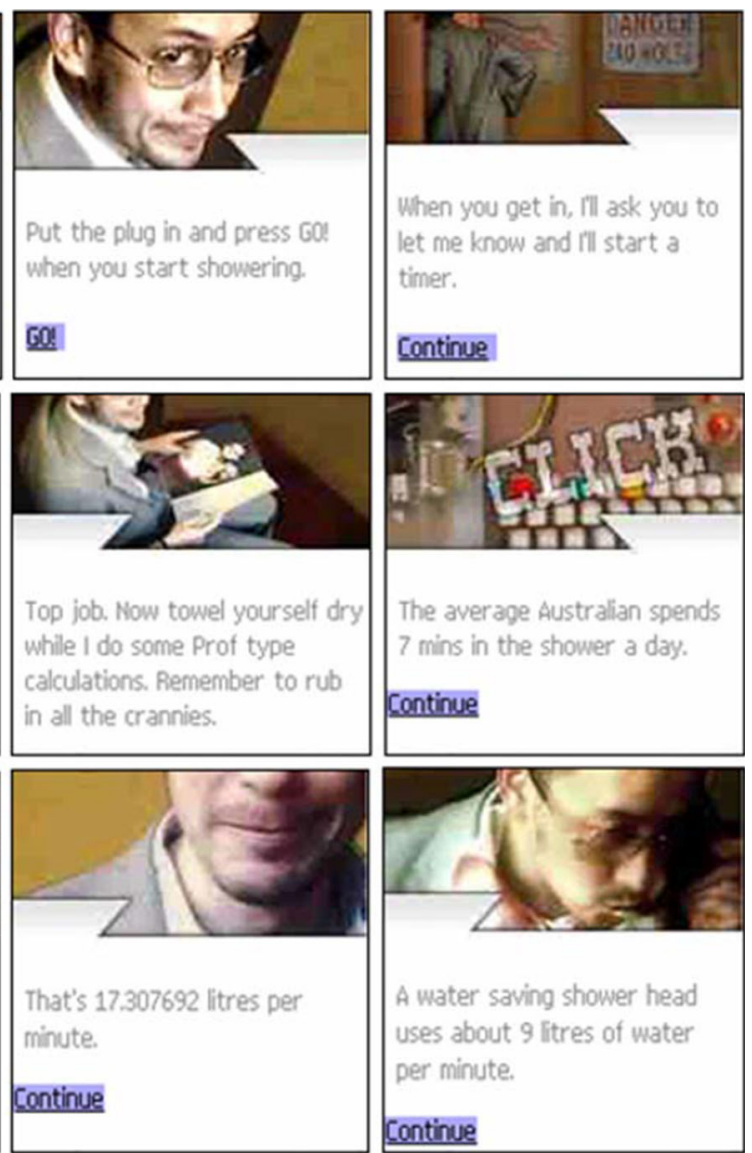

humour and the way in which he engaged them in local activities: an aspect of the game that they would like to see expanded in future versions. Most players also felt that the 2-week game was too short. In terms of improvements, many players reported that they would have engaged even more with the game if activities were more tailored for them, there were more practical experiments, they were able to review their games, or activities were better tailored or for particular places.

\subsection{Bicker Manor}

Our first phase of trials had explored complementary approaches to engaging the public in environmental campaigns across a range of settings. We carried forward the lessons learned into a final integrated trial called Bicker Manor whose goals were to engage participants through narrative and character; encourage and direct them to undertake a wide variety of environmental activities, from casual information gathering to more significant experiments and interventions; and enable them to generate, contribute and share their own documentation of these activities. A key motivator of the design was the use of 
entertainment in order to encourage a move towards greener living and changing the players' practices of consumption [18].

Bicker Manor was driven by an overarching narrative in which a fictitious family named 'the Bickers' provided the backstory for the experience and enabled players to share a common goal. Each member of the Bicker family had their own perspective on climate change. Michaela, the teenage daughter, guided participants into the experience and provided an overall and relatively neutral commentary on events, including showcasing the 'best of' user-generated content. She introduced the campaign as a contest between her parents, Eve and Isambard, who offer directly contrasting lenses through which to view environmental issues. Initially, Michaela asks the public to 'Pick a side. Will you pick my mum Eve with her green evangelist views or my Dad Isambard with his thrifty green sceptic ways? It's up to you to decide.' When participants first sign up to take part, they are asked to choose either Eve or Isambard as their host character. Their choice directly influences their overall experience, as it affects the missions offered to them and the feedback they receive.

At the heart of Bicker Manor are missions, the core unit of activity from which the narrative is built. Eve and Isambard set various missions that invite participants to engage in activities such as answering questions, taking photos or making videos. Daily mini missions maintain ongoing engagement through lightweight activities that can be completed almost immediately. In contrast, mega missions are set every 4 days or so and involve undertaking and documenting more significant challenges.

Mini missions were intended to elicit a very prompt response and be completed in a short time period. There were three types of mini mission; Multiple Choice, Measure and Count and Answer and Explain. Multiple Choice missions were typically short questions with a choice of either two or four possible answers. Some of these missions had only one correct answer but others had no wrong or right answer but were an expression of an opinion. Measure and Count missions featured question that asked the participant to take a measurement and to respond with a numeric answer only, For example one mission asked the participant to count the number of non-energy-saving light bulbs in their home. Answer and Explain missions allowed the participant to respond with a free-text response; most commonly this would be a response to a question or statement posed by the mission. In the trial, Multiple Choice and Measure and Count were the most commonly used mission types as all of the platforms supported these mission types, but Answer and Explain was not supported on the SMS platform.

Mega missions were more involved missions intended to take place over a much longer period of time than mini missions (usually a few days). Mega missions could be built up using many different mini missions. Also, picture and video submission was supported for mega missions so that the participant could be asked to capture evidence or construct an artefact then submit a picture or video of it.

On completing a mission, a participant would receive personalised feedback contrasting their response with those of others (e.g. against the average or most popular). They could also review their history of completed missions as well as those of other participants.

Missions were delivered across three platforms: Web, mobile and Internet protocol television (IPTV) as shown in Fig. 5. The website was at the core of the experience and provided full functionality, enabling participants to respond to and complete all missions, view and rate user-generated content, and manage their profile and friends lists. Participants were also encouraged to register their mobile phone, after which they could respond to missions via SMS and MMS, including uploading images and videos. BT Vision, the broadband supported television service provided by BT, also enabled players to complete missions and view
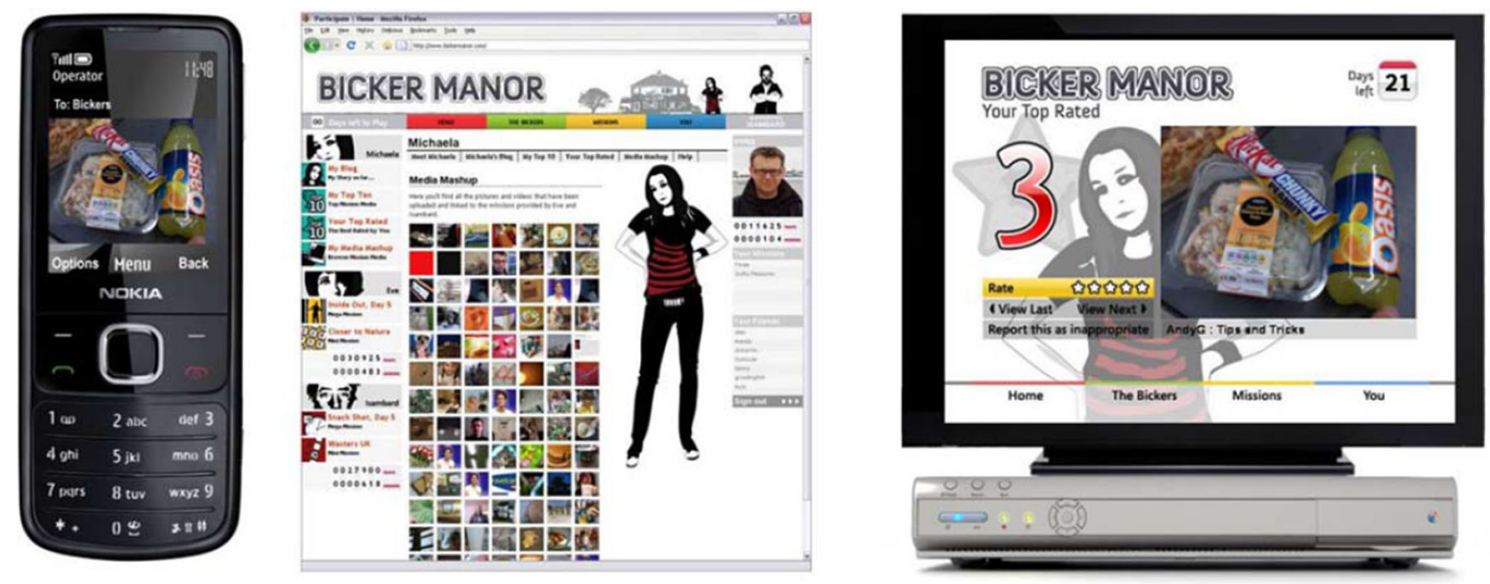

Fig. 5 Interfaces to Bicker Manor. Example on small mobile interface, Web and IPTV 


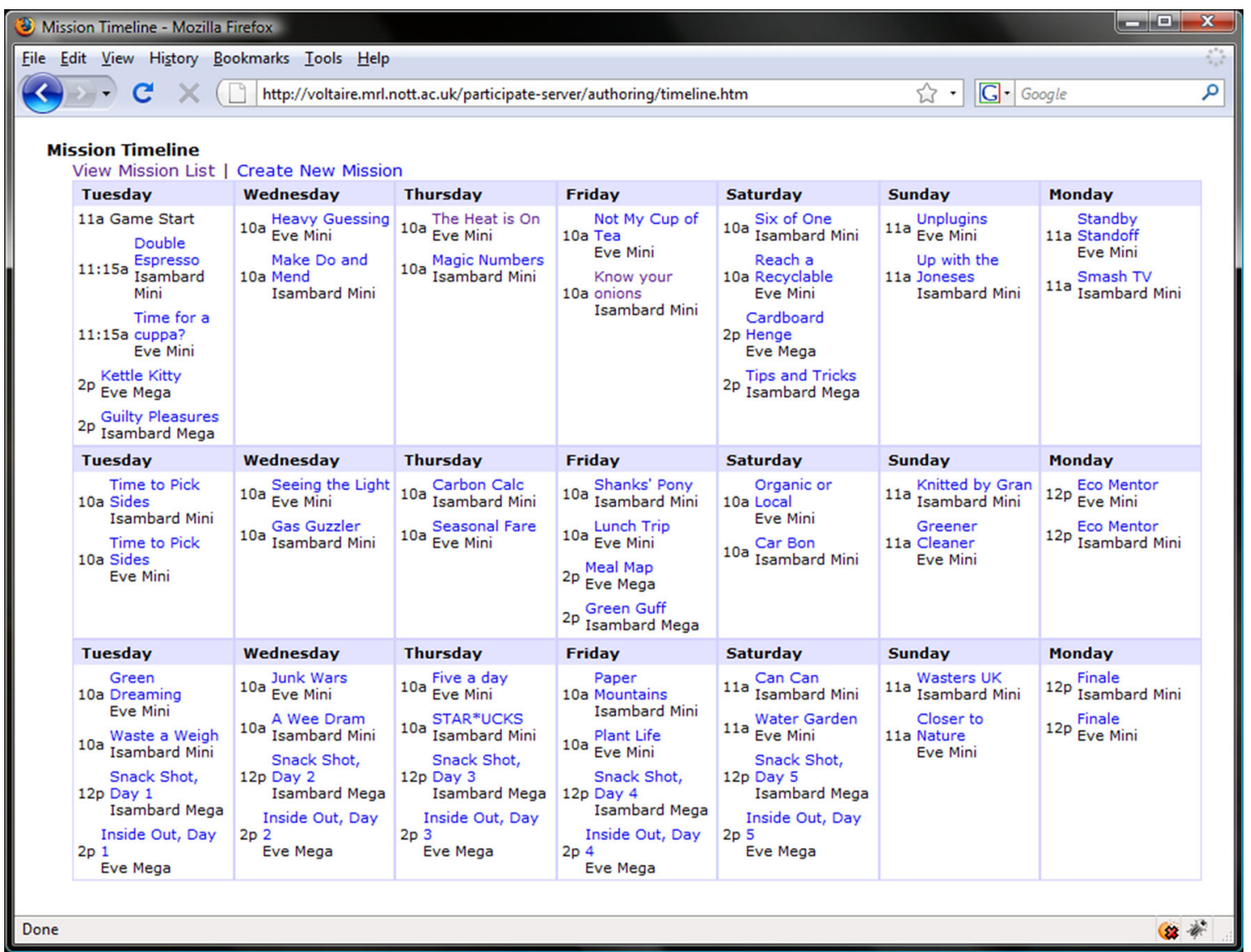

Fig. 6 Authoring and scheduling missions

and rate user-generated content. Email was used as a notification service to inform players of new missions that had been made available by Eve and Isambard.

We also created Web-based tools to support the distributed authoring and testing of missions, moderation of user-generated content and overall orchestration of the campaign. Figure 6 shows the top-level screen of the mission -authoring interface in which over 50 missions were allocated over a 21-day campaign. Each mission is given an ID and name, is either a mini or mega mission and is associated with either Eve or Isambard. Selecting a mission brings up further authoring pages that enable its particular details to be authored and configured.

We ran the pilot trial of Bicker Manor over a 3-week period, during which time 87 people signed up to take part. All 87 registered to use the website, 29 also registered to play via mobile, while 17 registered to use the BT Vision system. We gathered feedback in the form of system logs, questionnaires and ethnographic observation. In actuality, 50 people played using only 1 platform (Web), while 28 played on two platforms with 9 playing on all three platforms provided. Unsurprisingly, it was found that different platforms were favoured in different situations and contexts, with comments such as 'Web at work, BT Vision at home' and 'Mobile at work'. Many favoured using the website as their principal mode of interaction. This may have been partly due to the website being the only platform able to provide all the functionality offered by the campaign. However, other factors influencing this also included the relatively slow response of the BT Vision-based interface, players being unfamiliar with other Interactive Services provide on BT Vision, and the minimal richness of experience provided when playing via SMS. Some participants regularly swapped between platforms: 'I used the phone to reply to challenges and missions sent to me directly and I used the Web to get at other missions watch other people's videos and follow the story on the website' and 'BT Vision while I was relaxing in the living room at home Web at work', 'Both Web and mobile phone worked equally as well, but quite liked using BT Vision and could share with children'

A total of 2,213 missions were allocated directly via either Eve or Isambard whereas participants manually selected 670 missions. Of these, 1,261 missions were completed resulting in 138 UGC media items (free text, images and video) being submitted by participants. People reported taking part in the experience for typically 5-10 min a day, with the longest sustained activity taking about 
25 min on BT Vision. A number of participants said that they would have liked to complete more missions than were provided daily by the campaign. Some players commented that the timing of missions was too predictable and that this made it easier to ignore them-it may be that a degree of surprising interruption is an important part of sustaining longer-term engagement in such campaigns.

In terms of the narrative, participants generally appreciated the Eve, Isambard and Michaela characters, as they gave the experience a playful, contemplative edge. Many also appreciated the characterisation and humour, commenting that this helped persuade them to take on missions. However, a few found the content to be 'silly' or unworthy, the characters to be overly cynical, or the missions to be light on hard information or learning. In short, it appears that playful narrative and characterisation can be a powerful motivator, but that this needs treating with some caution. Future campaigns could provide a wider range of characters that offer different lenses onto the experience, some of which are quirky and playful as were Eve and Isambard, while others are more serious and informative, for example scientists, local planners or teachers.

\section{Understanding Bicker Manor}

There were three main foci in the evaluation of Bicker Manor:

1. One issue for us lies in understanding some of the cross-platform aspects of the trial:

Do people move between different platforms and why/ why not and how might we understand these emergent practices [19] in relation to the user living a greener lifestyle. Are there any temporal patterns to their activities and the ways in which they use different platforms? This might tie into previous data that we have gathered from experiences such as Day of the Figurines [20] and could help inform the design of future experiences that use multiple platforms, including decisions about when to schedule events. In general, the answers to these questions would emerge from analysis of questionnaires and system logs of interactions, although they may also derive from ethnographic observations where platform engagement can be understood in relation to ongoing courses of action.

2. We are also interested in studying collaboration, but this time within the 'family' (whatever that may be) as they engage within the campaign:

Do families share their participation?

- Why or why not?

- How is this structured?
- What factors-technical or otherwise-affect family participation?

- How is family participation organised in relation to their other ongoing affairs?

In large part, the answers to these questions would emerge from ethnographic studies of selected participants. An ethnographer focused upon this.

3. We were also interested in studying 'persuasion'how can a campaign such as this persuade people to change attitudes and behaviours? Some of the issues to look at here are:

- Is having a framework of missions a factor?

- Is having an overarching narrative a factor?

- Can we understand the role of humour/subversion?

\subsection{Approach}

Our approach was based on the triangulation between three separate strands of work:

Capturing and analysing system logs that reveal patterns of interaction/participation. This includes client-side and server-side logs.

Questionnaires that capture participant opinion. These questionnaires were designed by University of Nottingham with input from BT and the ethnographer and were followed up with interviews.

Ethnographic observation-including the use of video recording-using the Digital Replay System (DRS) to support e-social science. This supported the replay and annotation of combinations of video recordings and system logs (including sensor data).

\section{Capture and analysis of system logs}

\subsection{Usage statistics}

The statistics offer an overview of the 87 players-of whom 6 were developers/authors/moderators, 87 Web platform users, 29 mobile platform users, 17 IPTV platform users, 50 users with only one platform registered (Web), 28 users with two platforms registered, 9 users with three platforms registered.

In total 1,261 missions were completed as shown in Fig. 7, with 1,622 missions being allocated but timing out. 138 mega missions completed, 640 mega missions timed out, 961 mini missions completed and 935 mini missions timed out. 138 UGC media items (free text, images and video) submitted, 2,213 missions started automatically, 670 missions 


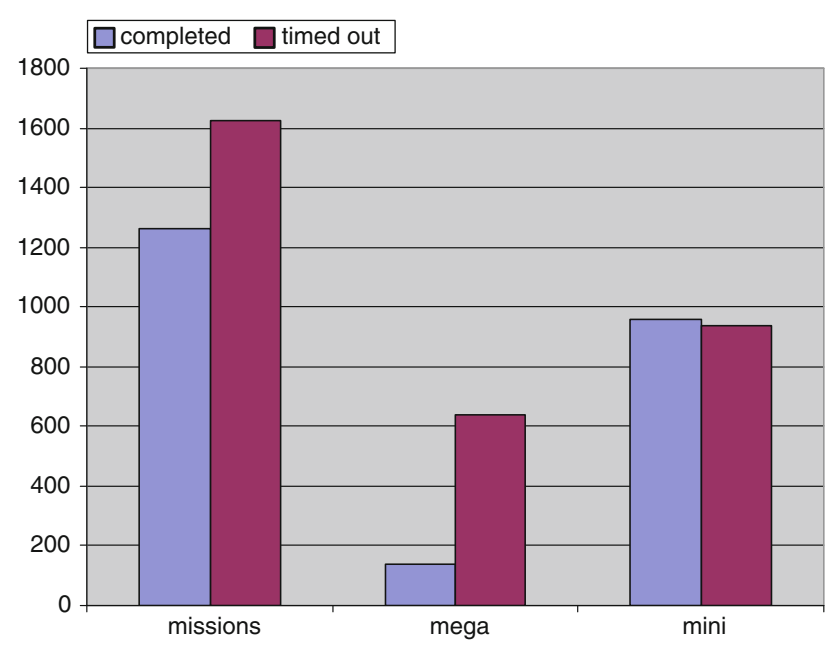

Fig. 7 Missions completed and timed out

\subsection{Questionnaire}

An online questionnaire was developed using the BSCW polling system. This was used as it had been successfully used in previous parts of the Participate project. The link to the questionnaire was emailed to all participants that took part in the November trial. The questionnaire consists of 30 questions. As previously stated, the questionnaire was designed as part of the whole evaluation and in so doing could be used to support the ethnography carried out and any system $\log$ results.

\subsection{Demographics}

Thirteen people answered the questionnaire: 8 of these were male and 5 were female. The average age of the respondent was 31 . Ten of the respondents were married or had a partner, while three were single. The respondents came from across the UK.

\subsection{Platforms}

All the participants had access to the Internet, while $38 \%$ had access to BT Vision and $92 \%$ had access to a mobile phone (of which $66 \%$ were MMS enabled). From this group, $69 \%$ of players used the Web to take part in Bicker Manor, while $23 \%$ used a mobile phone and $15 \%$ used BT Vision. $53 \%$ of people swapped between platforms, a further analysis of this can be found in the system log analysis. Respondents commented: 'I couldn't get my answers accepted when using mobile. BT Vision was too slow to respond', 'I used the phone to reply to challenges and missions sent to me directly and I used the Web to get at other missions watch other people's videos and follow the story on the website' and 'BT Vision while I was relaxing in the living room at home Web at work.' Ten respondents agreed that the platforms could be used together to take part in the trial, although one commented 'yes in theory, but not in practice' another participant said they participated more, because of this. Interestingly, $53 \%$ of respondents used different platforms at different times of the day and in different social settings, for example ' Web at work, BT Vision at home' and 'Mobile at work'. Seventy-six per cent $\%$ of respondents thought that the Web was the best platform to take part in Bicker Manor. Issues that were raised related to there being no prompting on BT Vision, lack of signal on mobile and people only using their mobile phone to make calls. Most people took part in the experience for 2-10 $\mathrm{min}$ a day, one person said 30 min was their maximum. This can be further explored in regard to the system logs and may have been dependent upon the type of mission that the participant took part in. Forty-six per cent or respondents would have liked to complete two missions per day twice as many as any other questionnaire category.

\subsection{Characters/identification}

Seventy-five per cent of respondents enjoyed playing with a character, people liked the 2 characters as it gave the experience a playful 'completive edge'. Other people thought that the characters were too cynical, very naggy and unconnected to the experience. Things that would have made the respondents interact with the experience were the ability to engage with other players and the characters, content not aimed at children, content that had real environmental info and more of a cohesive experience that enables people taking part in the experience what and why other people were doing mission. Overall $76 \%$ of the respondents enjoyed taking part in the experience, but $53 \%$ were not made anymore aware of larger environmental concerns. Eighty-four per cent $\%$ of respondents discussed the experience with other people. The responses suggest that people discussed Bicker Manor with their family and co-workers/colleagues. This is further supported by the results, $38 \%$ of people played with their family, but $61 \%$ said that they played on their own. Sixtynine per cent of the respondents found the experience funny, while others thought that it was 'silly', 'Wouldn't say humorous' and 'not really (humorous)'. Thirty-eight per cent thought that the humour in the game persuaded them to do the mission. One person reported that the humour made the game feel less worthy. Finally, $76 \%$ of people learnt something from taking part in the experience.

\subsection{Ethnography}

We developed a specific plan for how ethnography was used to feed into the evaluation of the various kinds of Participate platforms and their use. Ethnographic studies 
have a long-standing tradition in the situated evaluation of technologies. Ethnography more broadly involves ethnographers inhabiting specific settings over an extended period of time in order to understand how those settings are socially organised and how people themselves work to accomplish that social organisation. When it comes to evaluation, ethnography facilitates the development of an understanding of how technologies are actually adapted to and incorporated into local practice. The approach of looking at technology use in situ and working to understand how it is reasoned about in real-world contexts provides considerable data about how the technology might need to be improved or adapted to make it useable in those same kinds of real-world settings. In the case of Participate, the ethnography adopted a multi-pronged approach. The focus of the ethnographic studies was the public trials. The studies endeavoured to cover two basic phenomena: the engagement of participants with the trials in home settings and the work of moderation that decides what content becomes available to participants. Participants were studied across a range of different platform uses including, if possible, the use of IPTV, the use of Web browsers and desktop widgets and the use of mobile phones. Four participant groups were studied through in situ observation across four different settings and over the 4 weeks of the trials. These studies were augmented by telephone interviews over the same period. Additional resources drawn upon during this time equated to the analysis of the system $\log$ s and the selection of one household to study continuously across the whole of the trials period. Together, the ethnographic evaluation should facilitate an understanding of a range of concerns including:

- How different platforms are used across different kinds of situations and by various people.

- How engagement with the campaign is accomplished and made visible.

- How different local accountabilities, orientations and contingent interests influence the use of different platforms and various orders of engagement.

Taken together with other evaluation activities in Participate, the ethnographic evaluation should help to inform the future refinement and development of technology to support similar kinds of online campaigns.

\subsection{The ethnographic study of Bicker Manor}

For the duration of the Participate trial of the game focused on environmental issues, an ethnographic study of the game was conducted. This study was focused on capturing as much of the in situ engagement of players with the game as possible. To do this, we used three complementary strands:
1. An ongoing record of all the engagements with the game, conversations about and around the game, activities intersecting with the game, and so on, was kept throughout the game for two of the players. This was accomplished using the ethnographer as one of the players and his 18-year-old son as another player. This self-ethnographic approach was previously used with considerable success by the Mixed Reality Lab (MRL) during the course of the mobile text-messaging game Day of the Figurines [18].

2. In order to fully understand the nature of the domains [19] in which we were working, three separate households were recruited and visited during the course of the game for the purposes of (a) capturing their in situ engagement with the game and (b) interviewing them regarding their experience of the game so far, the fit of the game with their wider household routines and the technological organisation of the household.

3. Two other players were interviewed along similar lines, one recurrently at the end of each week of the gameplay, the other towards the end of the game.

The study subjects covered a range of different household configurations: one household with the parents working at home and four children ranging from 6 to 18 years old; two households with one parent out at work and the other largely at home with two children aged 3 and 5 , and 8 and 10, respectively; one household with a couple without children who both worked; and one single-person household who went out to work. This meant that gameplay was potentially intercepting a wide variety of different household circumstances and might be being engaged with at home, at work, or in transit between the two.

The study subjects crossed all three principal platforms for engagement with the game. Four of the households had access to BT Vision, though only one of them used it regularly for the game. All of them had access to the Internet and, for the majority, this was the primary platform used. One player used mobile phone-based SMS messages as the principal means of interacting with the game. Another player experimented with using a smartphone to use the Web interface to the game on a portable device. It should be noted that all subjects straddled at least 2 of the 3 principal platforms, none of them using 1 platform to the exclusion of all others.

\subsection{The ethnographic data}

The ethnographic study produced a total of $12 \mathrm{~h}$ of video and audio recordings, a body of field notes and a number of screenshots captured during specific interactions with the website. 


\subsubsection{Rationale}

There were three important reasons for engaging in the ethnographic study of Bicker Manor:

1. To capture some sense of the actual in situ lived experience of playing the game

2. To understand how gameplay was interwoven with everyday life

3. To get some comparison across the different platforms with regard to the preceding two points

The ethnographic data also provide us with a means of drilling down into other survey-based and statistical data gathered during the trial to understand what actual reasoning is in forming the results. All of the data are being subjected to ethnomethodological [21] analysis in order to tease out how playing of the game was ordered in relation to the participants' local production of their everyday affairs.

\subsection{Observations}

Observations extracted from the data cut along the following lines:

\subsubsection{Technical glitches}

These cover simple issues such as the persistent repetition of emails and more complex matters such as forced cheating where missions already completed were effectively reassigned to players, enabling the boosting of scores. Related matters such as scripting conflicts were also uncovered.

\subsubsection{Interface issues}

Just as with technical glitches, issues relating to the various interfaces were also uncovered as a matter of course. These include observations such as that the logical relationships between different parts of the website were not always found to be obvious, the use of the browser in BT Vision proved cumbersome and slow, and the SMS messages were found to be limiting in a variety of ways.

\subsubsection{Cross-Platform Interactions}

Unsurprisingly, perhaps, different platforms were favoured in different kinds of situations. More importantly, there was a strong push towards using the Internet on a PC as the principal mode. This was partly forced by the fact that the Internet was the only modality where all of the functionality of the game was available. However, other factors also played into this such as the poor speed performance of BT Vision (not to mention the fact that none of the players habitually used Vision for Interactive TV) and the minimal character of feedback available when playing via SMS.

\subsubsection{The interleaving of gameplay with everyday life}

This is one of the more complex topics, some key issues here relate to the fact that the game was both enormously predictable in when missions were going to be assigned and encountered and non-time critical (even for supposedly time-limited tasks). This made it easy to de-prioritise the game in relation to other activities and to shape interactions with it to one's own routine. This stands in contrast to other games we have observed and will have had an impact upon the character of engagement. It also had an impact on the reportability of the game and therefore upon its capacity to generate debate around the topics it raised.

\subsubsection{The game as a lived experience}

One of the most critical features to be explored here is the capacity of the game to generate engagement. This partly relates to some of the features already mentioned regarding prioritisation, reportability and the social nature of computing as factors in persuasion [22]. However, it also relates to matters such as players finding it frustratingly difficult to locate any competitive angle that might motivate them to engage more fully. Associated with this is a generally reported difficulty with being able to make the 'Friends' component of the game in any way meaningful. The latter point in particular would appear to be an important area for future development.

\section{Conclusion-structuring environmental campaigns}

Participate's varied trials have demonstrated a multiplicity of approaches to public campaigns, environmental or otherwise, which might potentially involve many different kinds of participants and technologies. It would be naïve to think that only the technological tools [22] impacted upon the users' behaviour and therefore we must take into consideration the complex set of social variables that influence how an individual's behaviour may be changed. In regard to our findings, we propose a generalised design and a 'three-layer' approach to structuring participation in such campaigns. We frame our conclusions within the relevant literature.

The public (individuals and families) use their personal devices to access environmental data and upload personal information about their attitudes, behaviours and local 
environments. As part of the campaign, the public would provide information (sensed, located, qualitative and opinionated data). The public would also engage with each other at a familial, community (Local group) and individual level. This would enable the campaign to be tailored by the campaign providers to meet the emerging needs of the Public, who in many ways would be driving the campaign through the provision and analysis of data (content). The Public represent the audience for the broadcasters that are engaged in the project, but in order to tailor content for that audience, perhaps in the form of missions, the broadcasters would need to understand the context that the missions would be used in, or the type of audience that they would be dealing with, in terms of demographics and interest/ focus. In this model, the Public are providing content in relation to their day-to-day lives.

Local groups (schools, science centres and visitor attractions) play a crucial role in engaging communities with particular issues [23] and encourage focused investigation of local settings using more specialised technologies such as mobile environmental sensors as part of school field trips or location-based media that enhance a site of special interest or a visitor centre. We propose a highly specialised use of data and tools for the Specialist layer, but we would envisage interplay between the provision of data (in terms of its use and analysis) from both the Public and the Specialist layers, both feeding into the Local-group level. From the three-layer model, we would expect to see the local groups, be they schools, wildlife groups [such as the Royal Society for the Protection of Birds (RSPB), for example] or community groups acting as the catalyst to the participation in regard to a local cause. The Local-group level of the model could in many respects act as the core participatory node, acting as a gateway between data Experts and the Public, but also between broadcasters and policymakers. Although we have outlined a three-layer model, it is clear that there would be varying degrees of crossover within this model, in particular between the Public and Local groups. It would be interesting to see how the different layers might engage with the different sorts of data that they encountered. With a key component of such campaigns being continued engagement, we expect that this role would fall upon the Local level of the model.

Experts (ecologists, scientists, policymakers and broadcasters) drive and shape the campaign in regard to the provision of specialist, expert, reliable and authoritative knowledge. They are raising issues, setting broad challenges, assimilating specialist information on a national or even global scale, and feeding it back to the local groups through broadcast and online services. It is worth bearing in mind that both the Public and Local groups in our model would be able to use the large, open data sets that are now available, and the tools to support the analysis of such data, in a way that relates to their concerns about the environment. It may be that the role that experts play is the delivery of specialised authoritative scientific data and understanding the relevance of this in a broader environmental context and at a governmental level.

We would suggest that a successful environmental campaign needs to engage all three layers and develop synergistic relationships between them, as exemplified by our pilots. We have also explored various factors that might motivate these different participants to engage. Social interaction is clearly a great potential motivator, as seen in the phenomenal spread of social networking applications such as Facebook, Twitter and others over recent years, and reflected in our pilots through the popularity of sharing data and media with friends and groups. It may be possible to take advantage of these large-scale social medial platforms [24] in order to deploy engagement frameworks and direct them to a given community. Community involvement needs a strategy, which relates to local people's interests and practices. As our other studies have shown, social media has in recent years been used as a tool to initially build a relationship with different communities of practice and interest [24].

In these studies, we also explored the role of narrative in driving a campaign and promoting engagement. Characters such as Prof. Tanda, Eve, Isambard and Michaela offer distinct lenses through which participants can view and debate complex issues and enable a campaign to raise opinions that might not be part of the current orthodoxy. Humour, realised through suggesting playful activities, using a quirky tone of voice, and even a degree of stereotyping in characterisation (in this case, the 'Mad Scientist'), also offers a route to delivering messages and information in a way that is not hectoring or patronising.

Participate has also introduced the mechanism of missions as a way of encapsulating a wide range of activities that can respond to a 'call for action'. Different types of missions, from answering multiple choice questions, to conducting a science experiment, to counting objects around the house, to recording a short video, constitute the basic units of engagement from which a campaign narrative can be structured, with different types of missions being scheduled at different times (e.g. daily or weekly) or following on from one another to steadily lead participants up a 'chain' of increasing participation. Finally, missions can be scheduled for delivery across multiple platforms (mobile, Web and TV) so as to enable participation at different times and locations and address the preferences of different participants.

At the start of this article we said, "we believe that pervasive computing can ultimately engage millions of people in mass participation environmental campaigns, 
raising awareness of environmental issues, supporting education, activism and democracy, and delivering environmental data on a scale never before possible' and it must be noted how rapidly social media, such as Facebook, Twitter and Google+, combined with the advancement of mobile, sensing and locative technologies have enabled this area to develop. One only has to look at the plethora of campaigns being run, for example by organisations such as Friends of the Earth and the RSPB which not only bring together Public and Specialist knowledge but also combine social media and pervasive/ubicomp technologies in order to allow the discussion, provision, provenance and analysis of data relating to the environment, in order to support education, scientific discovery and governmental lobbying.

In summary, while existing approaches to participatory sensing and social networking already provide some of the essential ingredients of environmental campaigns, our work in Participate has explored how these can be complemented by other elements. These are playful narratives composed from flexible missions that can be delivered across multiple platforms, to create structures that bring together the public, local groups and experts. While Participate has clearly been focused on environmental campaigns, these same ideas might also be applied to other kinds of campaign, from democracy to marketing, and ultimately might lead to a new form of media experience that combines elements of broadcasting, games and social networking to create mass participatory events.

Acknowledgments We gratefully acknowledge the support of the Engineering and Physical Sciences Research Council (EPSRC) and Technology Strategy Board (TSB) for funding this work through the Participate project. We would also like to thank the many researchers who have contributed to Participate as well as our external partners Kew Gardens and the many schools who were involved.

Open Access This article is distributed under the terms of the Creative Commons Attribution License which permits any use, distribution, and reproduction in any medium, provided the original author(s) and the source are credited.

\section{References}

1. Tarek A et al (2007) Mobiscopes for human spaces. IEEE Pervasive Comput 6:20-29

2. Burke JA et al (2006) Participatory sensing, presented at the World Sensor Web workshop. ACM Sensys, Boulder

3. Honicky R et al (2008) N-smarts: networked suite of mobile atmospheric real-time sensors. In: Proceedings of the second ACM SIGCOMM workshop on Networked systems for developing regions, Seattle, WA, USA

4. Mainwaring A et al (2002) Wireless sensor networks for habitat monitoring. In: Proceedings of the 1st ACM international workshop on Wireless sensor networks and applications, Atlanta, Georgia, USA
5. Schilit B et al (1994) Context-aware computing applications. In IEEE Workshop on mobile computing systems and applications, Santa Cruz

6. Joki A et al (2007) Campaignr: a framework for participatory data collection on mobile phones. Available: http://repositories. cdlib.org/cens/wps/770

7. Benford $S$ et al (2005) Bridging the physical and digital in pervasive gaming. Commun ACM 48:54-57

8. Froehlich J et al (2010) The Design of Eco-feedback Technology. In: Presented at the ACM conference on human factors in computing systems, Atlanta

9. Tomlinson B (2010) Greening through IT. MIT Press, Cambridge

10. Paulos E, Honicky R, Hooker B (2008) Citizen science: enabling participatory urbanism. In: Foth $\mathrm{M}$ (ed) Community integration and implementation Urban informatics. IGI Global, Hershey

11. Chamberlain A, Crabtree A, Rodden T, Jones M, Rogers $Y$ (2012) Research in the wild: understanding 'in the wild' approaches to design and development. Conference on designing interactive systems 2012, ACM DIS 2012: 795-796

12. Kanjo E et al (2008) MobGeoSen: facilitating personal geosensor data collection and visualization using mobile phones. Pers Ubiquit Comput 12:599-607

13. Woodgate D et al (2009) Using mobile and pervasive technologies to engage formal and informal learners in scientific debate. In: Goh TT (ed) Multiplatform e-learning systems and technologies: mobile devices for ubiquitous ICT-based education. IGI Global, Hershey, pp 196-214

14. Pierce J, Odom W, Blevis E (2008) Energy aware dwelling: a critical survey of interaction design for eco-visualizations. In: Proceeding of Australasian conference on computer-human interaction OZCHI '08, Cairns, Queensland

15. Paxton M, Benford S (2009) Experiences of participatory sensing in the wild. In: Proceedings of the 11th international conference on Ubiquitous computing, Orlando, Florida

16. Gustafsson A, Bång M, Katzeff C (2009) Evaluation of a pervasive game for energy engagement among teenagers. Computers in Entertainment (CIE), 7(4) Elsevier

17. Chamberlain A et al (2007) Professor Tanda: greener gaming \& pervasive play. In: Proceedings of the 2007 conference on designing for user eXperiences, Chicago

18. Van Vliet B, Chappells H, Shove E (2005) Infrastructures of consumption: Environmental innovation in the utility industries. Earthscan, London

19. Warde A (2005) Consumption and theories of practice. J Consumer Cult 5(2):131-154

20. Flintham M, Giannachi G, Benford S, Adams M (2007) Day of the figurines: supporting episodic storytelling on mobile phones. International conference on virtual storytelling. Springer, Berlin, pp $167-175$

21. Garfinkel H (1967) Studies in ethnomethodology. Prentice-Hall, Englewood Cliffs

22. Dourish P (2009) Print this paper, kill a tree: environmental sustainability as a research topic for human-computer interaction. Technical Report LUCI-2009-004, Laboratory for Ubiquitous Computing and Interaction, UC Irvine

23. Pearce JM, Smith W, Nansen B, Murphy J (2009) Smartgardenwatering: experiences of using a garden watering simulation. In: Proceedings of OzCHI 2009 conference, Melbourne

24. Chamberlain A, Crabtree A, Davies, M (2013) Community engagement for research: contextual design in rural CSCW system development. The 6th international conference on communities and technology 2013, C\&T 2013 Munich, Germany 